\title{
Group C streptococci isolated from throat swabs: a laboratory and clinical study
}

\author{
R F M Lewis, A E Balfour
}

\begin{abstract}
Aims-To determine the prevalence of $\beta$ haemolytic, Lancefield group $C$ streptococci in throat swabs taken in routine clinical practice, and correlate the species identified with presenting clinical features.

Methods-One year, laboratory based prospective study, using a questionnaire to elicit clinical information.

Results-4.4\% of throat swabs yielded group C streptococci, of which $38 \%$ belonged to $S$ equisimilis and $53 \%$ to $S$ anginosus-milleri group (SAM). Pyrexia was more common in patients with $S$ equisimilis, but other clinical features did not differ significantly between the two groups. No $\boldsymbol{S}$ zooepidemicus was isolated. Conclusions-Species identification of group C streptococci from throat swabs does not appear to be clinically useful in this patient population. However, the prevalence and spectrum of organisms is similar to that reported in $\mathbf{N}$ America, where studies suggest a possible role in some cases of severe pharyngitis. Observational studies such as this lack power to resolve the issue of pathogenicity, for which a placebo controlled trial of antibiotic treatment is ideally required.

(F Clin Pathol 1999;52:264-266)
\end{abstract}

Keywords: pharyngitis; group C streptococcus

The role of group C streptococci as a cause of sore throat has been debated at least since 1947, when a prospective study of over 3000 US army recruits admitted to hospital with respiratory tract infections revealed seven with both cultural and serological evidence of group C infection. ${ }^{1}$ Since then it has become clear that streptococci possessing the group C polysaccharide antigen are taxonomically diverse, with the number of species, as well as their nomenclature, still unclear. However, there is general agreement on a division into a large colony "pyogenic" group and a small colony "anginosus" group, ${ }^{2}$ the latter varying in its polysaccharide antigens and commonly referred to in Europe as Streptococcus milleri. ${ }^{3}$ Recent case-control studies from North America ${ }^{4-9}$ have revived interest in these organisms as potentially treatable causes of sore throat. We present data from a one year prospective study of throat swabs examined in one laboratory in Glasgow, in which $\beta$ haemolytic group $C$ streptococci were identified to species level, and the results compared with clinical features as recorded on a standard questionnaire.

\section{Methods}

The study was carried out in a hospital laboratory serving a mainly urban population in Scotland between June 1996 and June 1997. All throat swabs submitted for bacteriological examination were received in Charcoal-Amies transport medium ("Venturi" transport swabs, Bibby-Sterilin, Staffordshire, England). Swabs were cultured on two Columbia agar plates containing $5 \%$ horse blood. These were incubated overnight at $37^{\circ} \mathrm{C}$, one in air $+5 \%$ $\mathrm{CO}_{2}$ and one anaerobically. $\beta$ Haemolytic colonies were subcultured for purity and tested for polysaccharide antigens of Lancefield groups A, B, C, D, F, and G using a latex immunoagglutination test (Streptex, Murex Biotech, Dartford, England). Group C colonies were further identified by their biochemical profile using API 20 Strep (BioMerieux, Marcy L'Etoile, France), with computerised identification (API Lab-Plus software version 5.1).

Isolates were reported to the clinician as "group C Streptococcus ....... significance of results unclear," regardless of species identification. Sensitivity testing to penicillin, erythromycin, and trimethoprim was performed by a disc diffusion method, but results were withheld from the clinician and the "neutral" comment "sensitivities available from lab if required" substituted.

Clinical data were collected retrospectively by means of a short questionnaire sent to the requesting clinician a few days after the report had been issued. Information was sought on the presence or absence of the following features: cough, rhinorrhoea, throat exudate, cervical lymphadenopathy, and pyrexia. Details of recent antibiotic prescribing were also requested. The questionnaire was followed up where necessary by a telephone call.

Data were entered on to a spreadsheet (Microsoft Excel 5.0), and subsequent statistical analysis carried out using SPSS version 7.0 for Windows. We performed $\chi^{2}$ tests with Yates' correction on $2 \times 2$ tables; where numbers were small we used Fisher's exact test in addition.

Results

During the 12 month period of the study, 65 throat swabs of 1493 received (4.4\%) yielded group C streptococci. None of the 65 positive swabs were from hospital inpatients. Most were from young adults, with only one patient under the age of 15 years. Four of the 65 patients were found to have another microbiological cause for their sore throat (oral candidiasis in one,
Accepted for publication 4 January 1999 
Table 1 Clinical features in 54 patients with group $C$ streptococci in throat culture

\begin{tabular}{llll}
\hline Symptom & Present & Absent & No data \\
\hline Throat exudate & 20 & 31 & 3 \\
Cervical lymphadenopathy & 17 & 33 & 4 \\
Pyrexia & 12 & 34 & 8 \\
Cough & 3 & 45 & 6 \\
Rhinorrhoea & 1 & 47 & 6 \\
\hline
\end{tabular}

rubella in one, positive glandular fever screening test in two), and were excluded from analysis. A further three cases were excluded because no clinical data could be obtained.

Twenty two $(38 \%)$ of the isolates from the remaining 58 patients were identified as Streptococcus equisimilis, one as $S$ sanguis, and 31 $(53 \%)$ as $S$ anginosus-milleri group. Four strains could not be speciated with certainty from their biochemical profile, and these were also excluded from analysis.

The clinical features in the 54 evaluable patients are summarised in table 1 . Thirty three of the patients $(63 \%)$ were prescribed antibiotics empirically at presentation, a further seven $(13 \%)$ at a subsequent consultation, and $13(25 \%)$ received no antibiotics. Data were unavailable for one patient. There was no significant difference between patients with Group C $S$ equisimilis and those with Group C $S$ anginosus-milleri group with respect to cervical lymphadenopathy, throat exudate, or the prescribing of empirical antibiotics at first consultation. However, pyrexia was recorded by the doctor in eight of 19 patients with $S$ equisimilis compared with four of 27 with $S$ anginosus-milleri group ( $\mathrm{p}=0.05$ by Fisher's exact test).

\section{Discussion}

Faced with a $\beta$ haemolytic streptococcus from a throat swab, which turns out to belong to Lancefield group C, how should the medical microbiology laboratory proceed? Historically, all attention has been focused on the recognition of group A streptococci, so that treatment can be instituted to prevent the serious sequelae of rheumatic fever and post-streptococcal nephritis which occasionally follow throat infection with the predominant species of this group, $S$ pyogenes. The widespread introduction of susceptibility to a bacitracin disc as a screening test for the presence of $S$ pyogenes in throat swabs ${ }^{10}$ led to group C species (which are mostly bacitracin resistant) being ignored. ${ }^{11}$ Bacitracin susceptibility testing fell from favour as a screening test once latex agglutination methods had much simplified the procedure of determining the Lancefield group, but it had already been noted in 1969 that an animal species of bacitracin resistant, large colony group C streptococcus could cause sore throat, septicaemia, and post-streptococcal nephritis in humans. ${ }^{12}$ So far the small number of reported cases of infection with this organism, since named Streptococcus zooepidemicus, has been confined to those who have either been in close contact with farm animals, or have drunk unpasteurised milk. ${ }^{13}$ Among over 3000 patients with sore throat included in three recent North American series, only a single case of $S$ zooepidemicus was detected, ${ }^{58}$ and we have found none in the present study.

The other large colony group C streptococci which have been isolated from the human body belong to Streptococcus equisimilis, a species which also properly includes strains of Lancefield group G. ${ }^{14}$ Although this species has been described as a commensal in the pharynx, gut, and female genital tract, invasive disease is also well documented, ${ }^{15}$ and outbreaks have been reported from single strains (as judged by $\mathrm{T}$ protein typing), in one instance causing postpartum infection in a maternity unit, ${ }^{16}$ and in other instances food borne infection. ${ }^{17}$ Those strains from cases of overt infection which have been studied resemble $S$ pyogenes in expressing an $M$ protein which confers resistance to phagocytosis. Some of them also produce extracellular enzymes common to $S$ pyogenes such as streptolysin $\mathrm{O}$ and hyaluronidase, and invasive infection has been accompanied by antibody responses to these proteins. ${ }^{17}$ The extent to which these properties are shared by commensal $S$ equisimilis strains is at present unknown.

The SAM group of streptococci are variable in their polysaccharide antigens, and fall genotypically into three groups, for which the species names $S$ constellatus, $S$ anginosus, and $S$ intermedius have been proposed..$^{18}$ Strains of all three genotypes have been isolated from purulent lesions at a variety of body sites; possible pathogenic mechanisms are reviewed by Whitworth. ${ }^{19}$

Table 2 Comparative data on group $C$ streptococci from throat cultures in cases of pharyngitis

\begin{tabular}{|c|c|c|c|c|c|c|c|c|c|}
\hline \multirow[b]{2}{*}{ Reference } & \multirow[b]{2}{*}{$\begin{array}{l}\text { Year of } \\
\text { publication }\end{array}$} & \multirow[b]{2}{*}{ Study setting } & \multicolumn{3}{|c|}{ Patients with pharyngitis } & \multicolumn{4}{|c|}{ Control patients } \\
\hline & & & $n$ & $\begin{array}{l}\text { S equisimilis } \\
\text { isolated (\%) }\end{array}$ & $\begin{array}{l}\text { SAM group } C \\
\text { isolated }(\%)\end{array}$ & $n$ & $\begin{array}{l}\text { S equisimilis } \\
\text { isolated (\%) }\end{array}$ & $\begin{array}{l}S A M \text { group } C \\
\text { isolated (\%) }\end{array}$ & Comment \\
\hline 7 & 1990 & $\begin{array}{l}\text { Paediatric } \\
\text { outpatient clinic, } \\
\text { USA }\end{array}$ & 1730 & 0.7 & 0.9 & & $-\mathrm{ND}$ & - & $\begin{array}{l}\text { One case of } S \text { zooepidemicus } \\
\text { identified }\end{array}$ \\
\hline 8 & 1991 & $\begin{array}{l}\text { Paediatric } \\
\text { outpatient clinic, } \\
\text { USA }\end{array}$ & 255 & 5 & ND & 247 & 2.4 & ND & $\begin{array}{l}\text { Data also include group G } \\
\text { strains }\end{array}$ \\
\hline 5 & 1993 & $\begin{array}{l}\text { College students, } \\
\text { USA }\end{array}$ & 1480 & 3 & 11 & 227 & 2.2 & 11 & \\
\hline 6 & 1997 & $\begin{array}{l}\text { College students, } \\
\text { USA }\end{array}$ & 265 & 11 & 8 & 162 & 2 & 1 & \\
\hline $\begin{array}{l}\text { Present } \\
\text { study }\end{array}$ & & $\begin{array}{l}\text { General practice, } \\
\text { UK }\end{array}$ & 1486 & 1.5 & 2.1 & & $-\mathrm{ND}$ & - & \\
\hline
\end{tabular}


We have found group C streptococci from the throats of patients with pharyngitis to belong in roughly equal proportions to either $S$ equisimilis or the $S$ anginosus-milleri group (SAM). This may be compared with the results of recent North American studies (table 2), which with one exception do not lend any support to the hypothesis that either organism is responsible for sore throat. The exception is the 1997 study by Turner and colleagues, ${ }^{6}$ which differed in including only those patients (about a quarter of those who had throat swabs taken) who had definitive clinical evidence of pharyngeal exudate. Unfortunately, the identification methods used for group C streptococci in this paper, while distinguishing SAM group C from $S$ equisimilis, do not distinguish $S$ equisimilis from $S$ zooepidemicus. Nevertheless Turner's study suggests that there may be a subgroup of patients with severe pharyngitis where either SAM group C or $S$ equisimilis have a causal role, but that most studies to date suffer from the dilutional effect of too many cases of mild pharyngitis in which group $\mathrm{C}$ streptococci, though present, have no such role. The logical next step from these case-control studies is a prospective, placebo controlled trial of penicillin treatment for patients with exudative pharyngitis whose throat swabs yield $S$ equisimilis or SAM group C. Given the low prevalence of this situation, and the probable need to stratify patients by age ${ }^{20}$ and quantity of organisms isolated, ${ }^{6}$ this is not a light undertaking.

Pending the outcome of such a study, it seems to us inappropriate for the laboratory to report $S$ equisimilis or SAM group C from throat swabs at present, particularly at a time when the value of giving antibiotics at all in cases of sore throat is being increasingly doubted. ${ }^{21}$ At present, the only confirmed throat pathogen among the group C streptococci is $S$ zooepidemicus, which may be detected by its combination of $\beta$-glucuronidase activity, lactose and sorbitol fermentation, and failure to ferment trehalose. ${ }^{22}$ In view of its rarity, examination even for this organism may best be confined to cases where infection ".......is severe, invasive or followed by poststreptococcal glomerulonephritis, when there seems to be a link with animals, or when clusters occur," as suggested by those who first described the organism. ${ }^{13}$ If future trials of antibiotic treatment do incriminate either of the two common species of group C streptococci, it is worth noting that these four tests ( $\beta$-glucuronidase, lactose, sorbitol, and trehalose) will also identify both SAM and $S$ equisimilis.

1 The Commission on Acute Respiratory Disease. The role of Lancefield groups of beta-haemolytic streptococci in respiratory infections. N Engl F Med 1947;236:157-66.

2 Kilian M. Streptococcus and Lactobacillus. In: Balows A, Duerden BI, eds. Topley \& Wilson's microbiology \& microbial Duerden BI, eds. Topley $\mathcal{E}$ Wilson's microbiology of microbial
infections, 9th ed, vol 2. London: Edward Arnold, infections, 9th

3 Guthof O. Ueber pathogene "Vergruenende Streptokokken". Z Bakteriol 1956;166:553-64.

4 Meier FA, Centour RM, Graham L, et al. Clinical and microbiological evidence for endemic pharyngitis among adults due to group C streptococci. Arch Intern Med 1990; 150:825-9.

5 Fox K, Turner J, Fox A, et al. Role of Group C beta-haemolytic streptococci in pharyngitis: epidemiological study of clinical features associated with isolation of Group C streptococci. F Clin Microbiol 1993;31:808-11.

6 Turner JC, Hayden GF, Lobo MC, et al. Epidemiologic evidence for Lancefield group C beta-haemolytic streptococci as a cause of exudative pharyngitis in college students. $\mathcal{F}$ as a cause of exudative phary
Clin Microbiol 1997;35:1-4.

7 Cimolai N, MacCulloch L, Damon S. The epidemiology of beta-haemolytic non-group A streptococci isolated from the throats of children over a one-year period. Epidemiol Infect 1990;104:119-26.

8 Cimolai N, Morrison BJ, MacCulloch L, et al. Betahaemolytic non-group A streptococci and pharyngitis: a case-control study. Eur f Pediatr 1991;150:776-9.

9 Turner JC, Hayden GF, Kiselica D, et al. Association of Group C beta-haemolytic streptococci with endemic pharyngitis among college students. FAMA 1990;264:2644-7.

10 Maxted WR. The use of bacitracin for identifying group A haemolytic streptococci. F Clin Pathol 1953;6:224-6.

11 Ross PW, Christy SMK, Knox JDE. Sore throat in children: its causation and incidence. BMF 1971;ii:624-6.

12 Duca E, Teodorovici G, Rodu C, et al. A new nephritogenic streptococcus. F Hyg 1969;67:691-8.

13 Barnham M, Cole G, Efstratiou A, et al. Characterisation of Streptococcus zooepidemicus (Lancefield group C) from human and selected animal infections. Epidemiol Infect 1987;98:171-82.

14 Farrow JAE, Collins MD. Taxonomic studies on streptococci of serological groups $\mathrm{C}, \mathrm{G}$ and $\mathrm{L}$ and possibly related taxa. Syst Appl Microbiol 1984;5:483-93.

15 Ruoff KL Streptoccal diseases. In: Hausler WJ, Sussman M, eds. Topley \& Wilson's microbiology and microbial infections, 9th ed. London: Edward Arnold, 1998:266.

16 Teare EL, Smithson RD, Efstratiou A, et al. An outbreak of puerperal fever caused by group C streptococci. $\mathcal{J}$ Hosp Infect 1989;13:337-47.

17 Efstratiou A, Teare EL, McGhie D, et al. The presence of M-proteins in outbreak strains of Streptococcus equisimilis T-type 204. F Infect 1989;19:105-11.

18 Whiley RA, Beighton D. Emended descriptions and recognition of Streptococcus constellatus, Streptococcus intermedius, and Streptococcus anginosus as distinct species. Int f Syst Bacteriol 1991;41:1-5.

19 Whitworth JM. Lancefield group $\mathrm{F}$ and related streptococci. 7 Med Microbiol 1990;33:135-51.

20 Hayden GF, Murphy TF, Hendley JO. Non-group A streptococci in the pharynx. Am 7 Dis Child 1989;143:794-7.

21 Little P, Williamson I, Warner G, et al. Open randomised trial of prescribing strategies in managing sore throat. BMF 1997;314:722-7.

22 Efstratiou A, Colman G, Hahn G, et al. Biochemical differences among human and animal streptococci of Lancefield group C or group G. F Med Microbiol 1994;41:145-8. 